\title{
Recurrent Childhood Spinal Cord Neoplasm
}

National Cancer Institute

\section{Source}

National Cancer Institute. Recurrent Childhood Spinal Cord Neoplasm. NCI Thesaurus. Code C71712.

The reemergence of a spinal cord neoplasm in childhood after a period of remission. 